\title{
Cost analysis and evaluation of risk factors for postoperative pneumonia after thoracic and cardiovascular surgery: a single-center study
}

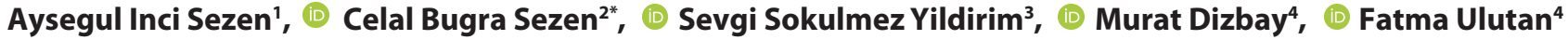

'Department of Infections Diseases and Clinical Microbiology, Haseki Research and Education Hospital, Istanbul, Turkey ${ }^{2}$ Department of Thoracic Surgery, Yedikule Chest Diseases and Thoracic Surgery Research and Education Hospital, Istanbul, Turkey

${ }^{3}$ Ankara Occupational and Environmental Diseases Hospital, Ankara, Turkey

${ }^{4}$ Department of Infections Diseases and Clinical Microbiology Faculty of Medicine, Gazi University, Ankara, Turkey

\begin{abstract}
Background: Postoperative pneumonia increases costs associated with inpatient stay, treatment, laboratory testing, and imaging, thereby increasing total healthcare costs. The aim of this study was to determine risk factors in patients who develop pneumonia after thoracic and cardiovascular surgery, evaluate relationships between these risk factors and cost, and conduct a cost analysis of postoperative pneumonia.
\end{abstract}

Materials and Methods: 111 patients who underwent major thoracic or cardiovascular surgery between June 2009 and March 2014 were evaluated retrospectively. Patients who developed postoperative pneumonia $(\mathrm{p}=37)$ were compared with those who had no postoperative complications $(\mathrm{p}=74)$.

Results: 40 men and 71 women were included in the study. Mean length of hospital stay was 21 days for patients with pneumonia versus 10 days for patients without pneumonia $(\mathrm{p}<0.001)$. Significant risk factors for postoperative pneumonia were Charlson Comorbidity Index $>2$, steroid use, high ASA score, presence of nasogastric tube, peripheral/central venous catheterization, postoperative heart failure/acute kidney failure, total parenteral nutrition, late postoperative mobilization, and prolonged ventilation and intubation $(\mathrm{p}<0.05)$. Postoperative pneumonia was associated with significantly higher mortality rate and total cost $(\mathrm{p}<0.001$ for both). The mean cost of treatment for patients with and without postoperative pneumonia was $8211.7 \mathrm{TL}$ and $3917.5 \mathrm{TL}$, respectively $(\mathrm{p}<0.001)$. There were statistically significant differences between the two groups in the costs of surgery, radiology, antibiotics, and cultures ( $\mathrm{p}<$ 0.001 for all). Correlation analysis between risk factors and cost revealed that prolonged intubation, late mobilization, and lack of respiratory rehabilitation exercises were associated with higher costs $(\mathrm{p}<0.05)$.

Conclusions: Postoperative pneumonia significantly increases costs. Identifying and mitigating these factors will reduce both the incidence of infection and the associated costs. Because infection control measures help avoid infection and thereby infection-related costs, it is critically important to support infection control activities and prevent nosocomial infections.

Key Words: cost analysis, pneumonia, prognostic factors

Corresponding Author*: Celal Bugra Sezen, MD. Health Sciences University, Yedikule Chest Diseases and Thoracic Surgery Education and Research Hospital, Kazlicesme Mah., Belgrad Kapı Yolu No: 1, 34020, Zeytinburnu, Istanbul, Turkey.

E -mail: info@bugrasezen.com Phone: +90 5531605531

Doi: $10.26663 /$ cts.2019.00011

Received 01.03.2019 accepted 02.04.2019 


\section{Introduction}

Nosocomial infections are difficult to treat due to both patient characteristics and resistance in the infectious agents. In addition to increasing length of hospital stay and mortality rates, nosocomial infections create a substantial economic burden due to increased costs. The results of the Study on the Efficacy of Nosocomial Infection Control (SENIC) conducted in the mid-1970's provided a large database on this subject. This report, which was published in 1992 and included data on direct annual medical costs, brought attention to healthcare-associated infections and the significance of costs associated with them [1].

Although preventive measures have improved along with other medical advances, nosocomial pneumonia is an important problem in Turkey. There is not enough study on this subject in Turkish literature. There have been very few studies conducted in Turkey on the development and costs of postoperative pneumonia in particular. There are not enough studies in the literature on the risk factors and costs associated with pneumonia after cardiothoracic surgery, which accounts for a substantial proportion of postoperative pneumonias.

The present study evaluated risk factors for the development of pneumonia after cardiothoracic surgery and the relationships between these factors and cost.

\section{Materials and Methods}

A total of 111 patients who were diagnosed with pneumonia after undergoing a major operation in the thoracic and cardiovascular surgery department between 01 July 2009 and 31 March 2014 were evaluated retrospectively. Thirty-seven patients who developed pneumonia were compared with 74 patients with no additional complications during treatment. Thirty-six (32.4\%) of the patients had pneumonectomy due to non-small cell lung carcinoma in the thoracic surgery department and 75 patients $(67.6 \%)$ underwent coronary artery bypass and valve surgeries in the cardiovascular surgery department. Pneumonia was diagnosed based on the criteria for ventilator-associated pneumonia (VAP) published by the Centers for Disease Control and Prevention (CDC) [2]. The study was approved by the institutional review board and conducted in accordance with the principles of the Declaration of Helsinki.

\section{Microbiological Examination}

For mechanical ventilation in intensive care units (ICUs), secretions are removed using a closed system. Endotracheal aspirate sampling was done by discon- necting patients from the respirator and collecting a deep tracheal aspirate sample using a special cannula with a sterile reservoir. For patients who underwent bronchoscopy, bronchoalveolar lavage and protected specimen brush samples were analyzed. Sputum culture was obtained from patients who were not intubated. Bacteria were identified using conventional methods as well as BBL Crystal Enteric/Nonfermenter ID Kit and BBL Crystal Gram-Positive ID Kit (Becton \& Dickinson, USA) systems.

Antibiotic susceptibility of the isolates was assessed using the Kirby-Bauer diffusion method according to Clinical and Laboratory Standards Institute (CLSI) standards. Antimicrobial agents were selected for antibiotic susceptibility testing based on CLSI recommendations. For resistant microorganisms, sensitivity to tigecycline and sulbactam-cefoperazone, which are not included in the CLSI recommendations, was evaluated based on EUCAST and literature data.

Comorbidities were evaluated using the Charlson Comorbidity Index (CCI). The patients' demographic characteristics and risk factors were gathered by retrospectively evaluating routinely collected data from the hospital records system. Postoperative complications and mortality was defined as deaths and complications that occurred within the first 30 days after surgery or after hospital admission.

We evaluated treatment-related expenses in terms of surgery, laboratory, radiography, antibiotic, culture, and inpatient stay costs, and analyzed correlations between postoperative pneumonia and these costs.

\section{Statistical Analysis}

Numerical variables were evaluated using mean and standard deviation or median (minimum-maximum) and categorical variables using number and percentage. Comparisons of numerical data between groups was done using independent samples t-test when parametric assumptions were met and the Mann-Whitney U test when these assumptions were not met. Kruskal-Wallis test was used in comparisons of multiple groups. Chisquare test or Fisher's exact test was used to determine whether the categorical variables differed between groups. Associations between numerical variables were analyzed using Spearman's correlation coefficient. All analyses were done using SPSS (version 22, SPSS Inc., Chicago, IL, USA) package software. Level of significance was accepted as $p<0.05$. 


\section{Results}

There were 40 women (36\%) and 71 (63.9\%) men in the study. Mean length of hospital stay was 11 days. Further analysis showed that mean length of stay was 21 days ( $\min =4, \max =55$ days) for patients with pneumonia versus 10 days for patients without pneumonia $(\mathrm{p}<$ $0.001)$. Distributions of the patients' demographic and clinical features are shown in Table 1.

\begin{tabular}{lcc}
\multicolumn{3}{l}{ Table 1. Demographic characteristics of the patients. } \\
\multicolumn{4}{l}{$\mathrm{n}$} & $\%$ \\
Gender & \multicolumn{3}{l}{} \\
Male / Female & $40 / 71$ & $64 / 36$ \\
Age (years) & $62.61 \pm 12.69$ years \\
$<65$ & 64 & 57.7 \\
$>65$ & 47 & 42.3 \\
Smoking history (Pack/Year) & $36.5 \pm 17.5$ \\
Never & 11 & 9.9 \\
Active & 16 & 14.4 \\
Former & 84 & 75.7 \\
Department & & \\
Thoracic surgery & 36 & 32.4 \\
Cardiovascular surgery & 75 & 67.6 \\
CCI & & \\
0 & 13 & 11.7 \\
1 & 19 & 17.1 \\
2 & 61 & 55.0 \\
3 & 13 & 11.7 \\
4 & 4 & 3.6 \\
5 & 1 & 0.9 \\
Pneumonia +/- & $37 / 74$ & $33.3 / 66.7$
\end{tabular}

In our study, $64.7 \%$ of pneumonectomy patients had complications. Significant risk factors for pneumonia were identified as thoracic surgery, $\mathrm{CCI}>2$, steroid usage, high ASA score, postoperative nasogastric tube usage, central venous catheterization, postoperative early mobilization, and TPN (Table 2).

The mortality rate was $17.4 \%$ overall $(n=20)$ and $48.6 \%(n=18)$ among patients with pneumonia. Eleven of the deceased patients (14.3\%) had cardiovascular surgery and $9(24.3 \%)$ had thoracic surgery.

Cost analysis of patients with postoperative pneumonia revealed a significant difference in surgery costs between patients with and without pneumonia. Laboratory costs increased proportionately in patients with pneumonia (628.7 TL [91.2 - 3,443.1 TL]; p < 0.001) (TL $=$ Turkish lira). The costs of radiological tests (chest $\mathrm{x}$-ray and CT) were significantly higher in patients with pneumonia (136.5 TL [0 - 1,500.8 TL]; $\mathrm{p}<0.001]$. The mean cost of antibiotic therapy was $90.4 \pm 58.6 \mathrm{TL}$ for patients without pneumonia and 2,326.8 $\pm 3,293.1 \mathrm{TL}$ for patients with pneumonia $(\mathrm{p}<0.001)$. The mean cost of cultures was $10.4 \pm 21.0 \mathrm{TL}$ in patients without pneumonia and $121.7 \pm 146.8 \mathrm{TL}$ in patients without pneumonia $(\mathrm{p}<0.001)$. These findings indicate that pneumonia is associated with higher antibiotic and culture costs. Cost of inpatient care was also significantly higher in patients with pneumonia due to their longer hospital stays. The mean overall cost for patients who had postoperative pneumonia was 8,211.7 TL $(2,639.6$ - 35,950.0 TL). This was twice the overall cost of patients who did not develop pneumonia. Comparison of costs for deceased and surviving patients showed that costs were significantly higher for patients who died. Factors associated with higher costs in our study were prolonged intubation, prolonged immobility, lack of respiration physiotherapy, and increased need for inotropic agents ( $<<0.001 ; \mathrm{p}<0.001 ; \mathrm{p}=0.009 ; \mathrm{p}=0.023)$.

\section{Discussion}

The SENIC project remains one of the most extensive studies to evaluate the effectiveness of nosocomial infection control [3]. Data from SENIC indicated that healthcare-associated infections occur in approximately 4.5 per 100 hospital admissions and incurred a cost of 4.5 billion dollars [4]. Cost analysis studies are limited and generate broadly varying data due to the use of different metrics for cost assessment. In addition, most studies do not estimate losses resulting from loss of labor productivity and decreased quality of life, instead basing calculations on direct costs only. The most common approach in healthcare-related cost analysis studies is to compare costs calculated through observational epidemiologic follow-up of infected and uninfected patients [3]. In the present study, we retrospectively evaluated the effect of pneumonia after major thoracic and cardiovascular surgery on costs.

In developing countries like Turkey, both hospital infection rates and resistance rates are 3-5 times higher than the global average [5]. For this reason, hospital infections and prevention policies are especially pressing issues in economically developing countries. This is because nosocomial infections extend length of hospital stay by 10 days, increase hospital costs by $5-12$ thousand dollars, and most importantly, cause a 2- to 3-fold increase in mortality compared to global averages, and the majority of these infections are preventable [5-7]. 
Table 2. Risk factors for pneumonia.

\begin{tabular}{|c|c|c|c|c|}
\hline \multicolumn{2}{|l|}{ Variable } & Pneumonia - n (\%) & Pneumonia + n $(\%)$ & $P$ value \\
\hline \multirow[t]{2}{*}{ Sex } & Male & $47(63.5)$ & $24(64.9)$ & \multirow{2}{*}{1} \\
\hline & Female & $27(36.5)$ & $13(35.1)$ & \\
\hline \multirow[t]{3}{*}{ Age (years) } & & $62.4 \pm 12.4$ & $63.0 \pm 13.5$ & 0.809 \\
\hline & $<65$ & $45(60.8)$ & $19(51.4)$ & \multirow{2}{*}{0.342} \\
\hline & $>65$ & $29(39.2)$ & $18(48.6)$ & \\
\hline \multirow[t]{2}{*}{ Department } & Thoracic surgery & $18(50)$ & $18(50)$ & \multirow{2}{*}{0.010} \\
\hline & Cardiovascular surgery & $56(74.7)$ & $19(25.3)$ & \\
\hline \multirow{2}{*}{$\mathrm{CCI}$} & $0-1$ & $28(37.8)$ & $4(10.8)$ & \multirow{2}{*}{0.003} \\
\hline & $>2$ & $46(62.2)$ & $33(89.2)$ & \\
\hline \multicolumn{2}{|c|}{ Steroid use } & $1(1.4 \%)$ & $5(13.5 \%)$ & 0.015 \\
\hline \multicolumn{2}{|c|}{ Hospitalization in the last 6 months } & $18(24.3 \%)$ & $5(13.5 \%)$ & 0.282 \\
\hline \multicolumn{2}{|c|}{ Antibiotic use in the last 6 months } & $11(14.9 \%)$ & $8(21.6 \%)$ & 0.533 \\
\hline \multirow[t]{3}{*}{ ASA score } & 2 & $36(48.6)$ & $11(29.7)$ & \multirow{3}{*}{0.025} \\
\hline & 3 & $38(51.4)$ & $24(64.9)$ & \\
\hline & 4 & 0 & $2(5.4)$ & \\
\hline \multicolumn{2}{|c|}{ Postoperative nasogastric tube } & $1(1.4)$ & $9(24.3)$ & $<0.001$ \\
\hline \multicolumn{2}{|c|}{ Peripheral artery catheterization } & $16(21.6)$ & $15(40.5)$ & 0.036 \\
\hline \multicolumn{2}{|c|}{ Central venous catheterization } & $54(73)$ & $34(91.9 \%)$ & 0.020 \\
\hline \multicolumn{2}{|c|}{ Surgery duration (minutes) } & $330(35-480)$ & $240(60-540)$ & 0.074 \\
\hline \multirow{2}{*}{ Surgery type } & Open & $74(100)$ & $36(97.3)$ & \multirow{2}{*}{0.333} \\
\hline & Thoracoscopic & 0 & $1(2.7)$ & \\
\hline \multirow{2}{*}{ Surgery status } & Emergent & $1(1.4)$ & $1(2.7)$ & \multirow{2}{*}{1} \\
\hline & Elective & $73(98.6)$ & $36(97.3)$ & \\
\hline \multicolumn{2}{|c|}{ Need for inotrope } & $11(14.9 \%)$ & $9(24.3 \%)$ & 0.337 \\
\hline \multicolumn{2}{|c|}{ Day of mobilization } & $3.32 \pm 16.94$ & $11 \pm 13.16$ & $<0.001$ \\
\hline \multicolumn{2}{|l|}{ TPN } & - & $17(45.9 \%)$ & $<0.001$ \\
\hline
\end{tabular}

One of the main objectives of our study was to identify the effect of nosocomial infections on length of stay. In our study, length of stay increased by approximately 2 -fold in the presence of pneumonia ( $\mathrm{p}<$ $0.001)$. A review of national and international studies revealed that nosocomial infection extended length of stay by 2 to 33.5 days, usually in the range of $15-20$ days. The most comprehensive meta-analysis on this subject, performed by Durand-Zaleski et al. [8] evaluated more than 40 studies performed only in ICUs and showed that the nosocomial infections extended length of stay by 5 to 21 days. The Pennsylvania Healthcare Cost Containment Council in the USA, which has conducted one of the most extensive studies on the subject, reported in 2012 that hospital infections add an average of 16.9 days to length of stay [9]. Mundyet al. found that VAP prolonged length of stay by 6 days, whereas Karaoğlan et al. reported an additional 15.7 days due to VAP $[10,11]$. Cocanour et al. [12] reported that the average length of stay was 6.4 days for intensive care patients without infection and 21.6 days for those with infection.

Another important aspect of our study is the correlation between nosocomial infection and mortality. The mortality rate was significantly higher among patients who developed postoperative pneumonia than in patients with no infection ( $48.6 \%$ vs. $2.7 \%$ ). In a study conducted in ICUs, Madani et al. [13] found that mortality rates were $75.1 \%$ higher in catheter-associated bloodstream infections, $56.7 \%$ higher in VAP, and $18.7 \%$ higher in urinary tract infections. Erbay et al. [14] detected a significant difference in mortality between patients with 
and without VAP in the ICU. Furthermore, in a review by Yalçın on cost analyses of nosocomial infections, it was determined that reported additional mortality due to nosocomial infections varied from $4 \%$ to $33 \%$ [15]. Patients who undergo major surgery in the thoracic and cardiovascular surgery departments are distinct because they are older, usually have multiple comorbidities and risk factors, and are immunodeficient due to malignancy and treatment.

Thomas et al. [16] reported a 30-day mortality rate of $5.7 \%$ in patients with lung cancer who underwent pneumonectomy. The postoperative complication rate was $33 \%$. Sezen et al. [17] had a pneumonia rate of $18.8 \%$ in complementary pneumonectomy patients. In our study, $64.7 \%$ of pneumonectomy patients had complications. Complication rate and pneumonia rate were higher than in literature. We think that is due to preoperative selection criteria of our patients. In our study, comorbidities were observed to be more common in patients who performed pneumonectomy. On the other hand, we did not evaluate the preoperative general conditions of these patients.

In their meta-analysis on post-cardiac surgery VAP, He et al. [18] noted that it is necessary to improve cardiac and renal functions, treat chronic pulmonary disease, and control pulmonary hypertension preoperatively to reduce the risk of pneumonia and avoid aggressive antibiotic treatment. In our study, we found that risk of postoperative pneumonia increased in patients with a $\mathrm{CCI}>$ 2. Preoperative steroid use was also found to increase the risk of pneumonia.

The main aim of our study was to determine the additional cost burden caused by nosocomial infections. Additional costs due to nosocomial infections are a major burden on the healthcare system in developing countries, as in developed countries. It was reported that nosocomial infections added 28.4-33.8 billion dollars in costs to the USA healthcare system in 2007 [3]. In the UK, the annual additional cost of nosocomial infections to hospitals alone was 1 billion pounds [19].

In our study, the average total hospital cost was calculated as 3,917.5 TL for patients who did not have postoperative pneumonia and 8,211.7 TL for patients who developed pneumonia, which is a 2 -fold increase. In a meta-analysis by Stone et al. [20], one of the most extensive reviews on the subject, the highest costs relat- ed to nosocomial infection were due to catheter-associated bloodstream infections (38,703 USD), followed by pneumonia (17,677 USD). In the same study, the cost of surgical site infection was 15,646 USD, and the average cost attributable to infection was 13,973 USD. In another study by Kollef et al., the cost for patients who developed VAP in the ICU was 39,828 USD [21]. Meriç et al. [22] in a 2008 study determined that extra cost due to nosocomial infections in the ICU was 2,503 USD, while Hançer et al. determined in 2009 that the additional cost attributable to bloodstream infections alone in the ICU was 14,045 USD [23]. In a study performed by Rosenthal et al. in 2005, total additional cost was 2,255 USD and antibiotics cost a further 996 USD [24]. Some researchers have claimed that hospitalization costs were the most important factor increasing cost, whereas others implicated the cost of antibiotics. In the present study, antibiotics accounted for $38.9 \%$ of the total average additional cost of 2,327 TL. We believe that selecting appropriate treatment and administering treatment for the appropriate duration may be important steps in the reduction of hospital costs.

In our study, we found that hospitalization costs for patients with pneumonia increased by 2.18 -fold and 1,223 TL compared to patients without pneumonia, and hospitalization was the second most expensive item (30.6\% of total cost) after antibiotics. In contrast to our results, because labor costs are much higher in Europe and the USA compared to Turkey, hospitalization and service costs account for the largest proportion of hospital costs in studies conducted in those countries. In a study performed in the UK, it was reported that general hospital costs and nursing and care costs comprise approximately $64 \%$ of the total additional costs, while a study performed in Belgium showed that $58 \%$ of total cost was attributable to prolonged length of stay $[25,26]$.

Infection control measures can prevent costly infections. However, better access to personnel and financial resources are needed to support infection control activities and prevent nosocomial infection. To highlight these needs, it is important for studies on hospital epidemiology and healthcare-related outcomes to demonstrate the financial burden of nosocomial infections [27]. Costs can also be reduced by restricting antibiotic use and encouraging the rational use of medicines. Without rational drug use, infection control programs cannot be effective [28]. 


\section{Limitations of the study}

This study was retrospective and included a small number of patients. The main limitations are that patients were recruited from two different surgical departments and our cost analysis did not take into account loss of labor productivity. The inclusion of only pneumonectomy patients apart in thoracic surgery creates bias.

As a conclusion, postoperative pneumonia significantly increases healthcare costs. Identifying and mitigating these factors will reduce both the incidence of infection and the associated costs. Because infection control measures help avoid infection and thereby infection-related costs, it is critically important to support infection control activities and prevent nosocomial infections.

\section{Declaration of conflicting interests}

The authors declared no conflicts of interest with respect to the authorship and/or publication of this article.

\section{Funding}

The authors received no financial support.

\section{References}

1. Haley RW. The development of infection surveillance and control programs. Hosp Infect 1992; 3: 63-77.

2. Horan TC, Andrus M, Dudeck MA. CDC/NHSN surveillance definition of health care-associated infection and criteria for specific types of infections in the acute care setting. Am J Infect Control 2008; 36: 309-32.

3. Scott RD. The direct medical costs of healthcare-associated infections in US hospitals and the benefits of prevention 2009.

4. Martone WJ, Jarvis WR, Culver DH, Haley RW. Incidence and nature of endemic and epidemic nosocomial infections. In: Bennett JV, Brachman PS, eds.Hospital Infections.3rd ed. Boston, Mass: Little Brown \& Co; 1992:577-96.

5. Rosenthal VD. Device-associated nosocomial infections in limited-resources countries: Findings of the International Nosocomial Infection Control Consortium (INICC). Am J Infect Control. 2008; 36 :S171.e7-12.

6. Stone PW. Economic burden of healthcare-associated infections: an American perspective Expert Rev Pharmacoecon Outcomes Res 2009; 9: 417-22.

7. Alp E, Kalin G, Coskun R, Sungur M, Guven M, Doganay M. Economic burden of ventilator-associated pneumonia in a developing country. J Hosp Infect 2012; 81:128-30.
8. Durand-Zaleski I, Chaix C, Brun-Buisson C. Costs of nosocomial infections in the ICU and impact of programs to reduce risks and costs. Clin Pulm Med 2002; 9: 33-8.

9. Health P, Cost C, Council C. The Impact of Healthcare-associated Infections in Pennsylvania. 2012.

10. Mundy L. Hospital Epidemiology and Infection Control 2.nd Edition. Lippincott Williams and Wilkins; 1999.

11. Karaoglan H, Yalcin AN, Cengiz M, Ramazanoglu A, Ogunc D, Hakan R, et al. Cost analysis of ventilator-associated pneumonia in Turkish medical-surgical intensive care units. Infec Med 2010; 18: 248-55.

12. Cocanour CS, Ostrosky-Zeichner L, Peninger M, Garbade D, Tidemann T, Domonoske BD, et al. Cost of a ventilator-associated pneumonia in a shock trauma intensive care unit. Surg Infect (Larchmt) 2005; 6: 65-72.

13. Madani N, Rosenthal VD, Dendane T, Abidi K, Zeggwagh AA, Abouqal R. Health-care associated infections rates, length of stay, and bacterial resistance in an intensive care unit of Morocco: findings of the International Nosocomial Infection Control Consortium (INICC). vol. 2. 2009.

14. Erbay RH, Yalcin AN, Zencir M, Serin S, Atalay H. Costs and risk factors for ventilator-associated pneumonia in a Turkish university hospital's intensive care unit: a case-control study. BMC Pulm Med 2004; 4: 3.

15. Yalçın AN. İ.Ü. Cerrahpaşa Sürekli Tıp Eğitimi Etkinlikleri Hastane Enfeksiyonları Korunma ve Kontrol. Dizi No: 60. n.d.

16. Thomas PA, Falcoz PE, Bernard A, Le Pimpec-Barthes F, Jougon J, Brouchet L, et al. Bilobectomy for lung cancer: contemporary national early morbidity and mortality outcomes. Eur $\mathbf{J}$ Cardiothorac Surg 2016; 49: e38-43; discussion e43.

17. Sezen CB, Kocaturk CI, Bilen S, Kalafat CE, Aker C, Karapinar K. Long-term outcomes of completion pneumonectomy for non-small cell lung cancer. Acta Chir Belg 2019:1-6. doi: 10.1080/00015458.2018.1527567.

18. He S, Chen B, Li W, Yan J, Chen L, Wang X, et al. Ventilatorassociated pneumonia after cardiac surgery: A meta-analysis and systematic review. J Thorac Cardiovasc Surg 2014; 148: 3148-55.

19. De Angelis G, Murthy A, Beyersmann J, Harbarth S. Estimating the impact of healthcare $\square$ associated infections on length of stay and costs. Clin Microbiol Infect 2010; 16: 1729-35.

20. Stone PW, Larson E, Kawar LN. A systematic audit of economic evidence linking nosocomial infections and infection control interventions: 1990-2000. Am J Infect Control 2002; 30: 145-52. 
21. Kollef MH, Hamilton CW, Ernst FR. Economic impact of ventilator-associated pneumonia in a large matched cohort. Infect Control Hosp Epidemiol 2012; 33: 250-6.

22. Meric H. Eskişehir Osmangazi Üniversitesi Tıp Fakültesi Hastanesi genel cerrahi, beyin cerrahi, göğüs cerrahisi, kalp damar cerrahisi, yanık ünitesi, iç hastalıkları, nöroloji yoğun bakım ünitelerinde gelişen hastane enfeksiyonları, risk faktörlerine bağlı mortalite hızı ve maliyet üzerine etkisinin araştırılması Eskişehir Osmangazi Üniversitesi Tıp Fakültesi, Enfeksiyon Hastalıkları AD, Uzmanlık tezi, 2008.

23. Hançer M. Yoğun Bakımlarda Kan Dolaşımı Enfeksiyonu Gelişen Hastalarda Maliyet Analizi. Dokuz Eylül Üniversitesi Tıp Fakültesi, Enfeksiyon Hastalıkları ve Klinik Mikrobiyoloji AD, Uzmanlık tezi,, 2009.

24. Rosenthal VD, Guzman S, Migone O, Safdar N. The attributable cost and length of hospital stay because of nosocomial pneumonia in intensive care units in 3 hospitals in Argentina: a prospective, matched analysis. Am J Infect Control 2005; 33: 157-61 .
25. Plowman R, Graves N, Griffin MAS, Roberts JA, Swan A V, Cookson B, et al. The rate and cost of hospital-acquired infections occurring in patients admitted to selected specialties of a district general hospital in England and the national burden imposed. J Hosp Infect 2001; 47: 198-209.

26. Vrijens F, Hulstaert F, Van de Sande S, Devriese S, Morales I, Parmentier Y. Hospital-acquired, laboratory-confirmed bloodstream infections: linking national surveillance data to clinical and financial hospital data to estimate increased length of stay and healthcare costs. J Hosp Infect 2010; 75: 158-62.

27. Yalcin AN. Socioeconomic burden of nosocomial infections. Indian J Med Sci 2003; 57:450.

28. Daschner F. Cost-effectiveness in hospital infection control lessons for the 1990s. J Hosp Infect 1989; 13: 325-36. 